ISSN 2236-0859

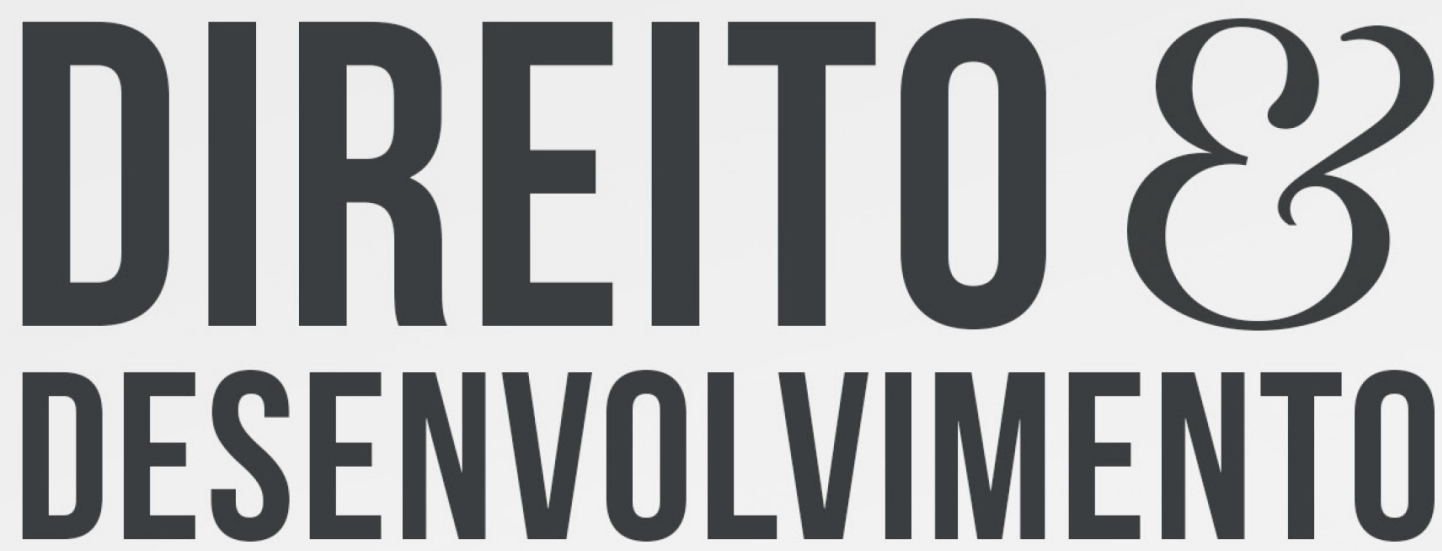

REVISTA DO PROGRAMA DE PÓS-GRADUAÇÃO EM DIREITO MESTRADO EM DIREITO E DESENVOLVIMENTO SUSTENTÁVEL

\title{
A INTERFACE DIALÉTICA ENTRE A DEMOCRACIA E A GLOBALIZAÇÃO
}

MARIA BEATRIZ ESPIRITO SANTO MARDEGAN

ARTUR CÉSAR DE SOUZA

WALKIRIA MARTINEZ HEINRICH FERRER 


\section{A INTERFACE DIALÉTICA ENTRE A DEMOCRACIA E A GLOBALIZAÇÃO}

\section{THE DIALECTIC INTERFACE BETWEEN DEMOCRACY AND GLOBALIZATION}

Recebido: 22/06/2020

Aprovado: 03/11/2020

\author{
Maria Beatriz Espirito Santo Mardegan ${ }^{1}$ \\ Artur César de Souza ${ }^{2}$ \\ Walkiria Martinez Heinrich Ferrer ${ }^{3}$
}

\section{RESUMO:}

A pesquisa intenta deslindar a relação dialética entre a democracia e a globalização, num processo simbiótico que envolve uma série de atores, estatais e não estatais, que se interagem e se influenciam reciprocamente. O ensaio aborda a contextualização histórica do processo democrático, desde a democracia direta da antiguidade grega, ressurgindo após dois mil anos, sob o paradigma de democracia representativa, evoluindo hodiernamente para a democracia semiindireta. A seguir, o estudo relata as diversas perspectivas ideológicas sobre a democracia, bem como os entraves enfrentados no processo de democratização na sociedade globalizada. Analisa o panorama histórico da globalização, sobretudo a partir da segunda metade da década de 1980, com o surgimento de novas tecnologias de comunicação e informação, com a redução dos custos dos meios de transporte, o desenvolvimento da internet e uma acentuada interdependência econômica mundial. A partir de então, aludido fenômeno passou de uma dimensão restritamente econômica, a uma realidade mais ampla e profunda, a qual inclui a ciência e tecnologia, as relações sociais, políticas e culturais. Destaca a possibilidade da relativização da soberania estatal diante da interdependência multifacetada do processo de globalização, concluindo que o processo da ampliação da democracia deve, necessariamente, estar condicionado à redução das disparidades sociais, uma vez que os princípios democráticos ficam demasiadamente inócuos quando a democracia é reduzida à simples regime político. Outrossim, a história tem demonstrado que extremas desigualdades sociais funcionam como um fator limitativo do processo solidificador da democracia mundial.

Palavras-chave: Democracia. Globalização. Contextualização. Antíteses Sociais.

1 Graduada em Direito pela Universidade Estadual de Londrina. Mestre em Direito Negocial - área de concentração em Direito Processual Civil, pela Universidade Estadual de Londrina. Pós graduada em Direito Penal e Processual Penal, pela Universidade Estadual de Londrina. Pós graduada em Direito Civil e Processual Civil, pela Universidade Norte do Paraná. email: biamlf@yahoo.com.br 2 Pós-doutor pelas seguintes Universidades: Università Statale di Milano - Itália (2007); Universidad de Valência - Espanha (20o8); Universidade Federal de Santa Catarina (UFSC) 2008. Faculdade de Direito da Universidade de Lisboa - Portugal (2013). Doutor em Direito das Relações Sociais pela Universidade Federal do Paraná - UFPR (2005) Doutorando em Filosofia pela Universidade de Barcelona - UB. Pesquisador da CAPES Possui mestrado em Direito Negocial pela Universidade Estadual de Londrina (2001). Professor do Curso de Mestrado e Doutorado da Universidade de Marília - UNIMAR Professor em Direito Processual Civil pela UNIFIL Juiz Formador da Escola da Magistratura Federal do Tribunal Regional Federal da $4^{\text {a }}$ Região - EMAGIS Juiz Formador da ENFAM no Curso de Ética e Deontologia Atualmente é juiz federal. email: arturcesarsouza@gmail.com

3 Graduação em Ciências Sociais (1989), Mestrado (1996) e Doutorado (2001) em Educação, Pós-doutorado em Sociologia do Trabalho (2019) pela Universidade Estadual Paulista Júlio de Mesquita Filho - Marília-SP. Docente titular do Programa de Pós-graduação em Direito da Universidade Marília. Coordenação do Núcleo Integrado de Pesquisa e Extensão - NIPEX/UNIMAR. Coordenação do Programa Institucional de Iniciação Científica- PIIC/UNIMAR, representante institucional do PIBIC/CNPq na Universidade de Marília. email: nipex@unimar.br 


\begin{abstract}
:
Theresearchattemptstounravel thedialectical relationship betweendemocracyandglobalization, in a symbiotic process that involves a series of actors, state and non-state, that interact and influence each other. The essay addresses the historical contextualization of the democratic process, from the direct democracy of greek antiquity, resurging after two thousand years, under the paradigm of representative democracy, evolving today to semi-indirect democracy. Next, the study reports the diverse ideological perspectives on democracy, as well as the obstacles faced in the process of democratization in the globalized society. It analyzes the historical panorama of globalization, especially from the second half of the 1980s, with the emergence of new communication and information technologies, the reduction of the costs of means of transport, the development of the internet and a marked global economic interdependence, when this phenomenon has gone from a strictly economic dimension to a broader and deeper reality, which includes science and technology, social, political and cultural relations. Highlights the possibility of relativizing state sovereignty in the face of the multifaceted interdependence of the globalization process, concluding that the process of expanding democracy must necessarily be conditioned to the reduction of social disparities, since democratic principles are too innocuous when democracy is reduced to the simple political regime. Furthermore, history has shown that extreme social inequalities work as a limiting factor in the solidifying process of world democracy.
\end{abstract}

Keywords: Democracy. Globalization. Contextualization. Social Antitheses.

\title{
1 INTRODUÇÃO
}

O estudo objetiva analisar a relação dialética multifacetada entre democracia e a globalização, a qual é influenciada por uma variedade de atores, que tanto podem constituir num fator de estímulo à sua promoção, como um elemento de pulverização e extenuação de seus caracteres.

Constata-se que as implicações da democracia no processo de globalização têm sido muitas vezes heterogêneas: ora promovem valores democráticos de estabilidade e pacificação mundial; ora sugerem desintegração, com práticas políticas, econômicas ou sociais não alinhadas aos princípios democráticos.

Analisa-se o contexto histórico do processo democrático, desde democracia direta ateniense, passando pela democracia representativa contemporânea, evoluindo para a necessidade de uma democracia semi-indireta, com mecanismos de aprimoramento da representatividade popular.

Analogicamente, o trabalho perquire o desenvolvimento da globalização, como um fenômeno de extraordinária interdependência das relações econômicas em nível mundial, de integração social, cultural e política entre os países, impulsionado pela redução de custos dos meios de transporte e de comunicação entre os países e pelo desenvolvimento da tecnologia e da internet.

Afere-se, ainda, que o êxito deste processo global de democratização pressupõe a somatória de alguns fatores, como o fortalecimento das instituições democráticas e da sociedade civil, o comprometimento das autoridades políticas com os autênticos fundamentos democráticos, a atuação diligente das organizações e comunidades internacionais, a existência de processos eleitorais competitivos e transparentes, a efetiva alternância de poder, o respeito 
a direitos e garantias fundamentais, dentre outros coeficientes que atuam como instrumentos de estabilidade democrática e pacificação social a nível global.

Insta ressalvar, por sua vez, que a função dos Estados Democráticos no cenário globalizado consiste também em instrumentalizar a conquista da justiça social e respeito a direitos fundamentais nas suas relações internacionais, minimizando os abismos existentes referentes às antinomias sociais.

A pesquisa utilizará o método histórico dedutivo, correspondente à extração discursiva do conhecimento a partir de premissas gerais aplicáveis à temática proposta, com a finalidade de apresentar possíveis soluções para a problematização que envolve o tema. O estudo se pautará na ampla pesquisa biográfica, podendo utilizar-se, ainda, da pesquisa informatizada, através da Internet, como meio de facilitação do acervo biográfico sobre a matéria.

\section{DEMOCRACIA: PANORAMA HISTÓRICO}

\subsection{Democracia Direta da Grécia Antiga}

Literalmente significando "o governo (kracia) do povo (demos)", a democracia surgiu no século $\mathrm{V}$ a.C. para denotar os sistemas políticos então existentes em Cidades-Estados da Grécia Antiga, como um regime de governo onde todas as decisões fundamentais à vida em comunidade eram tomadas em assembleia popular, reunindo todos os cidadãos, que assim participavam da vida política da polis. É o regime oposto da aristocracia (aristokratia), traduzida literalmente como "o governo dos melhores", forma de governo na qual o poder político era exercido pelos nobres, pessoas de confiança dos monarcas ou dos regentes iniciados, na perspectiva filosófica e política de Aristóteles (DAHL, 2001).

Denota-se, contudo, que tais regimes embora opostos, pragmaticamente, revelaram um paradoxo. No sistema político da Atenas Clássica, por exemplo, a cidadania democrática abrangia apenas homens livres, filhos de pai e mãe atenienses, e maiores de 21 anos. A maioria da população, representada por estrangeiros, escravos e mulheres era excluída da participação política. Uma forma direta, mas restritiva e elitista de participação popular, que, já na sua origem, surge como contradição ao genuíno ideal democrático (CABRAL NETO, 1997).

Assim, a democracia que, teoricamente deveria assegurar a igualdade política a todos os cidadãos, já em sua gênese evidenciava uma desigualdade substancial, limitando a participação popular nas decisões política.

Insta observar, no entanto, que a democracia grega antiga inaugurou um complexo de instituições que possibilitou consubstanciar, dentro dos limites da época, uma experiência de relevante expressão histórica. Além da participação direta na gestão pública, o sistema democrático ateniense continha instrumentos que permitiam fiscalizar e responsabilizar todos os ocupantes do corpo político.

\subsection{Democracia Representativa Contemporânea}

Após a derrota da experiência democrática grega, resultante da guerra desencadeada entre os anos 431 e 404 a.C., a democracia antiga desvaneceu do panorama político. Por toda a Idade Média e, sobretudo, a partir do século XV, com o fortalecimento dos ideais absolutistas os quais acabaram por respaldar os governos déspotas da época, houve um hiato histórico da democracia. 
Apenas dois mil anos depois, com o constitucionalismo moderno e com o federalismo, é que a democracia renasce no cenário político, não mais como paradigma de democracia direta ateniense, mas sob a modalidade de democracia representativa, contrapondo as convicções prescritas pela antiguidade grega. Madison, Hamilton e Joy expõem minuciosamente, na obra "O federalista", os fundamentos ideológicos da democracia representativa, como sendo a forma de governo em que o povo não participa diretamente da tomadas de decisões políticas do Estado, mas elegem seus representantes para que governem em seu nome (CABRAL NETO, 1997).

Sendo assim, a democracia indireta ou representativa é entendida como sendo aquela em que o povo, fonte primário de poder, não podendo dirigir diretamente o Estado, em virtude da extensão territorial, da complexidade e dos problemas sociais, econômicos e políticos existentes, outorga a função governamental a seus representantes, eleitos diretamente para um mandato temporário.

Importante ressaltar, contudo, que o grande desenvolvimento do pensamento democrático eclodiu na Europa nos séculos XVII e XVIII, no seio das revoluções burguesas. Essas revoluções engendraram e, ao mesmo tempo, fundamentaram o ideal liberal e a democracia moderna, a qual, no início, era avessa aos direitos democráticos mais abrangentes (SOUZA, 2006).

Como corolário, nos séculos XVII e XVIII, o modelo democrático difundiu-se como uma reação aos abusos de poder num contexto político caracterizado por governos autoritários. De fato, o Estado liberal surgiu no século XVIII em contraposição ao Estado absolutista. O modelo constitucional priorizava a liberdade do indivíduo e ao direito pleno de propriedade, assegurando princípios fundamentais para que a burguesia pudesse efetivar a manutenção do sistema. Caberia ao Estado apenas a manutenção da ordem, a preservação da paz e a proteção à propriedade privada.

Dessa forma, assentada nos princípios individualistas do liberalismo europeu, nas ideias progressistas desenvolvidas por John Locke, Jean Jacques Rousseau e Montesquieu, e consubstanciada nas Revoluções Inglesa (1688-1689), Americana (1776) e Francesa (1789), a democracia vem corroborada por tais ideais a ponto de TOCQUEVILLE (2014, p. 134) defini-la como a conjugação de liberdade e igualdade, como um paradigma político que impõe limites à atuação do Estado e ao mesmo tempo prescreve uma maior participação dos cidadãos no exercício do poder político.

Importante ressaltar que o pensamento liberal que servia de fundamento para a democracia moderna subordina a condição de cidadão à propriedade privada. A conquista da cidadania, nos moldes das formulações do liberalismo clássico, é condicionada à propriedade, sendo, pois considerado cidadão apenas o proprietário, conferindo uma perspectiva restritiva e discriminatória à concepção democrática liberal da época.

Conforme observa CERRONI (1993, p. 63), o escopo do liberalismo clássico não abrangia o sufrágio universal e igualitário entre homens e mulheres, tampouco a igualdade substancial entre os homens. Tais aspectos não faziam partes de suas bandeiras reivindicatórias. Mas foi, contudo, o liberalismo que teve o mérito de proferir o reconhecimento formal do princípio da igualdade, "(...) que abre as portas a todas as ulteriores reivindicações universalistas dos direitos. É por isso que o liberalismo, sem promover esta reivindicação, acaba por torná-la possível e posteriormente o acolhe".

Como consectário deste silogismo, o reconhecimento formal de que todos os homens são iguais perante a lei representou um significativo avanço histórico em termos de direitos humanos, servindo, posteriormente, como substrato ideológico para a conquista de direitos sociais. 
BOBBIO (1993, p. 44) expõe a interface relacional simbiótica entre a democracia e o liberalismo, afirmando que “(...) se é verdade que os direitos de liberdade foram desde o início a condição necessária para a direta aplicação das regras do jogo democrático, é igualmente verdadeiro que, em seguida, o desenvolvimento da democracia tornou-se o principal instrumento para a defesa dos direitos de liberdade".

Para a democracia, como espécie de regime político, o liberalismo forneceu subsídios teóricos para sua estruturação, prescrevendo a necessidade da formulação predefinida das regras eleitorais e políticas, com instrumentos legais que garantam a livre e igualitária competição dos indivíduos no processo eleitoral.

Afere-se, portanto, que a democracia moderna, em seu processo embrionário, assume a modalidade de democracia representativa, como a forma de governo na qual o representante eleito deve atuar em prol do bem estar do povo, como mandatário de seus interesses. A participação direta é inexoravelmente rechaçada por seus teóricos. Neste sentido, Montesquieu (1979), um dos seus principais expoentes, defendeu em sua obra "O Espírito das Leis" que: "O povo era excelente para escolher, mas péssimo para governar.”

Partindo de tais premissas, afere-se que a falha da democracia representativa não está no fato de ser um sistema político de representatividade popular, mas sim de não ser representativo o suficiente. Como corolário, o aprimoramento da democracia representativa demandou a ampliação da participação popular, com a criação de mecanismos e condições favoráveis para que o cidadão pudesse intervir e fiscalizar concretamente as decisões políticas de seu Estado.

\subsection{O Processo Evolutivo da Democracia Representativa para a Democracia Semi- Indireta}

ROUSSEAU (1983, p. 27), teorizando a respeito da sociedade francesa do século XVIII, prescreve em "O Contrato Social" a necessidade da adoção de um contrato, baseado na igualdade e na liberdade, como forma de legitimar todas as forças da sociedade, preconizando o brocardo de que os homens nascem livres e iguais, mas acabam escravizados pela modernidade civilizatória.

O teórico político reacende a necessidade da democracia refletir uma participação popular direta, formulando as primeiras críticas à democracia representativa, sob o argumento de que a soberania não poderia ser representada. Para Rousseau, o Estado possui a função soberana de exprimir a vontade geral, concluindo que sua autoridade deve expressar-se diretamente através da promulgação, pelo povo, das leis fundamentais, pois o simples ato de votar não traduz a genuína expressão da vontade popular.

Neste sentido, explana o filósofo:

É nula toda lei que o povo diretamente não ratificar; em absoluto, não é lei. O povo inglês pensa ser livre e muito se engana, pois só o é durante a eleição dos membros do parlamento; uma vez estes eleitos, ele é escravo, não é nada. Durante os breves momentos de sua liberdade o uso, que dela faz, mostra que merece perdê-la. (ROUSSEAU, 1983, p. 108).

Sob esta perspectiva, na concepção de Rousseau, era mister o ressurgimento de uma democracia direta, na qual o povo fosse capaz de expressar realmente a sua vontade no processo político decisório, conferindo destaque ao caráter educativo da participação popular. 
Entretanto, a evolução da sociedade moderna trouxe uma série de transformações reais que tornaram inviável pragmaticamente a democracia direta defendida por Rousseau. Para a concretização da aludida forma de governo, seria necessária a reunião de determinadas condições extremamente dificultosas de serem vivenciadas na prática, como: uma considerável simplicidade de costumes, um Estado extremamente pequeno e um elevado nível de igualdade entre as classes (ROUSSEAU, 1983, p. 86).

O próprio teórico tinha a compreensão da dificuldade de se pôr em prática os genuínos ideais democráticos, afirmando que: "Jamais existiu, jamais existirá uma democracia verdadeira" (ROUSSEAU, 1983, p. 84).

Como corolário de tais premissas, tem-se que a democracia direta não deve ser colocada como uma alternativa excludente à democracia representativa, mas como algo complementar, aprimorando os mecanismos de participação direta da população na conjuntura histórica atual. Uma espécie da democracia semi-indireta, adotada hodiernamente, por grande maioria dos Estados Democráticos, que mescla o modelo democrático da democracia representativa, com alguns institutos de participação popular direta, como o referendo popular e o plebiscito, e outros mecanismos.

Atualmente, a maioria dos Estados Democratas incorporaram em suas Constituições o sufrágio universal, igualitário e gratuito, institucionalizando a pluralidade de partidos políticos, a previsão legal de alternância de poder, bem como a prescrição de métodos procedimentais de aprimoramento da representatividade popular.

\section{DEMOCRACIA: DIVERSAS ABORDAGENS IDEOLÓGICAS}

É importante salientar que a definição de Democracia acaba por permitir inúmeras interpretações conceituais, diferentes valorações conferidas ao próprio entendimento de seu termo. Essa diversidade de conceitos justifica-se, segundo SOUZA (2006), pelas diferentes ideologias existentes, pelas diversas espécies de teorias, bem como pelas mais variadas pretensões dos agentes envolvidos nesta equação. Outrossim, é preciso considerar as gigantescas diferenças entre países e continentes. São diferenças culturais, históricas, geográficas, políticas e econômicas, de construção de processos civilizatórios que influenciam na concepção epistemológica unitária do processo democrático.

Assim, não obstante a divergência de acepções e teorias, esse ensaio ousa definir, hodiernamente, a Democracia como sendo um regime político em que todos os cidadãos elegíveis participam igualmente - diretamente ou através de representantes eleitos - na proposta, no desenvolvimento e na criação de leis, exercendo o poder de governança através do sufrágio universal.

Como corolário, pode-se afirmar que a institucionalização do Estado Democrático de Direito tem por escopo conceber a supressão da arbitrariedade no exercício das políticas públicas, a subordinação do poder ao império da lei, bem como o reconhecimento, em seu ordenamento jurídico, de direitos e garantias fundamentais.

Nesse contexto, BOBBIO (2000, p. 185) evidencia que a “(...) democracia é o governo das leis por excelência", com destaque para os princípios da legalidade, da liberdade e da igualdade, e efetiva tutela de direitos fundamentais.

Destaca-se, outrossim, a concepção de democracia, sob a perspectiva Kelseniana. O jurista austríaco Hans Kelsen explana que a democracia, em seu conceito mais puro, apresenta dois pilares essenciais: a liberdade e a igualdade. Nas palavras do autor, do ideal de que os indivíduos em sociedade são “(...) iguais, pode-se deduzir que ninguém deve mandar em 
ninguém. Mas a experiência ensina que, se quisermos ser realmente todos iguais, deveremos deixar-nos comandar" (KELSEN, 2000, p. 27).

Como corolário, a democracia, na concepção de Kelsen, consiste no modelo de organização social que permite à política sintetizar juridicamente esses dois princípios liberdade e igualdade - concluindo o jurista ser indubitavelmente esta a melhor forma de governo, ao mesmo tempo em que refuta qualquer espécie de ditadura partidária, seja ela de esquerda ou de direita.

Kelsen prescreve a ideia de democracia como uma convivência da maioria e da minoria no parlamento, discorrendo sobre a capacidade da minoria em influenciar nas decisões políticas. Sob esta perspectiva, a democracia outorga a cada conviç̧ão política a possibilidade de conciliação, através de ampla discussão, onde o procedimento da assembleia popular ou do parlamento, no processo de condução de governança, é dialético. A decisão política, portanto, seria resultado do consenso da maioria, garantidos os direitos fundamentais da minoria, com igualdade de condições de exposição, discussão e argumentação. Esta proteção da minoria, para Kelsen, é função essencial dos direitos e liberdades fundamentais, também denominados Direitos do Homem e do Cidadão, garantidos por todas as modernas Constituições Democráticas.

Assim, conforme observa DAHL (2001, p. 58), a discussão acerca do "governo de um, de poucos ou de muitos" leva ao inevitável silogismo que conclui ser a democracia a melhor forma de regime político até então existente, pois consoante assevera BOBBIO (2014, p. 39) “(...) se a política não servisse para melhorar a condição humana, seria pura expressão do poder".

Neste diapasão BOBBIO (2014, p. 39-40) destaca as vantagens da democracia em relação às demais espécies de regime de governo, dentre elas: evitar a tirania, assegurar direitos essenciais aos cidadãos, garantir a autodeterminação e autonomia moral do povo, a isonomia política e a alternância de poder, o desenvolvimento humano, a prosperidade e a paz social.

Pode-se dizer, portanto, que a democracia envolve diversos aspectos, como eleições efetivamentelivres, com suas idoneidades reconhecidasinternacionalmente, pluripartidarismo político, sufrágio universal, igualdade de votos, alternância de poder, o respeito a direitos e garantias fundamentais, mecanismos institucionalizados de participação popular direta, espécies de fiscalização popular nas contas públicas, descentralização administrativa, acesso à educação, à saúde, a direitos sociais básicos constitucionalmente garantidos, uma imprensa livre e sem censuras, o fortalecimento da sociedade civil organizada, das instituições e das organizações não governamentais.

Outro aspecto a se caracterizar o regime democrático corresponde ao fato de se tratar de um regime de governo no qual as regras do jogo estão predefinidas, assim como os direitos e garantias fundamentais de seus cidadãos são efetivamente respeitados, os quais, conforme assevera SARLET (2009, p. 29), encontram-se “(...) reconhecidos e positivados na esfera do direito constitucional” dos Estados Democráticos.

Essencialmente, tais benefícios, advindos de um regime político essencialmente democrático, seriam perfeitos se tal paradigma fosse vivenciado efetivamente em sua plenitude, onde as mais relevantes decisões políticas fossem efetivamente provenientes de uma coletividade de cidadania consciente e participativa.

Contudo, afere-se historicamente a enorme dificuldade dos Estados Democráticos colocarem em prática os atributos que caracterizam tal espécie de regime, suscitando a questionamentos sobre a real representatividade e participação popular, nos mais diversos países intitulados de democratas. Neste contexto, registra-se a célebre máxima do presidente 
norte-americano, Abraham Lincoln, em Gettysburg, em 1864, num cenário de guerra civil, defendendo o "governo do povo, pelo povo e para o povo".

A partir de então, as propostas de conceituação de democracia foram travestidas de tantas formas, descaracterizando-a de seus reais e genuínos fundamentos.

\section{OS ENTRAVES À DEMOCRATIZAÇÃO NO MUNDO GLOBALIZADO}

No processo de democratização do mundo globalizado, é importante destacar a relevância da denominada "Teoria da Paz Democrática", a qual defende o compartilhamento de regras de atuação e organização por parte dos países democráticos, prescrevendo a resolução pacífica de conflitos entre si. Com raízes na tradição kantiana, atualizada na versão universal de Fukuyama, os postulados centrais da teoria referem-se ao compartilhamento de normas e condutas, num contexto de competição política e resolução pacífica de suas diferenças (SOUZA, 2006).

Referida teoria defende a contribuição das organizações internacionais na construção da paz democrática, encarando a democratização como um instrumento pacificador necessário para a expansão da estabilidade a nível global.

Contudo, a história demonstra vários exemplos que questionam esta abordagem, tais como: as intervenções de caráter neoimperialista dos países desenvolvidos a países periféricos, economicamente mais fragilizados; o apoio a regimes autoritários; ou o uso de técnicas consideradas pouco democráticas, em prol de interesses nacionais exclusivamente econômicos das nações consideradas de Primeiro Mundo.

Citam-se, ainda, a maneira como os países democráticos ocidentais têm-se envolvido nos processos de transformação política na África ou na América Latina, conforme sua exclusiva conveniência político-econômica, ou ainda a relação de interesses exclusivamente financeiros entre o Ocidente e o Oriente Médio (SOUZA, 2006).

Outrossim, em alguns dos países considerados formalmente democráticos, a corrupção, as organizações criminosas, na esfera pública e privada, parecem mais fortalecidas que os compromissos democráticos assumidos pelos Estados.

Afere-se, pois, que muitos são os elementos de oposição e resistência ao avanço dos processos de democratização, evidenciando-se o desejo de grande parte dos Estados pela manutenção de privilégios de seletos grupos detentores dos poderes econômicos e políticos. Exemplos concretos que revelam como estruturas centralizadas de poder autoritário violam princípios democráticos, amparadas por governos travestidos de democráticos, sob o pretexto do desenvolvimento econômico e da segurança nacional. Práticas deturpadoras de uma democracia interpretada de maneira ambígua.

Percebe-se que esta "democracia totalitária" tem como modus operandi de seus governantes incutir nas grandes massas o ideológico de que apenas um líder carismático e populista pode consubstanciar e articular os verdadeiros interesses de seu povo. Assim, apesar das "democracias totalitárias" constituírem um claro e evidente desvio à lídima acepção de governo democrático, a sua existência demonstra a relação conflituosa entre a real democracia, lastreada no brocardo "governo do povo ou governo pelo povo", a qual promove a participação popular, com a versão travestida de democracia, a qual sob a falácia de agir em prol da população, sobretudo em períodos de grave crise econômica e social, sustentou os regimes autoritários - fascistas e comunistas - do século XX.

Em relação aos países árabes, de tradição islâmica, os quais se caracterizam, em regra, pela cisão dos sistemas político, legal e espiritual, a centralização do poder é considerada um 
atributo imprescindível para a manutenção da lei e ordem, o que os qualifica como "países pouco democráticos". As liberdades políticas e cívicas são muito limitadas e a participação popular e feminina é extremamente restrita. Os direitos humanos e as liberdades fundamentais também são constantemente violados.

Os líderes árabes, eleitos em processos eleitorais muitas vezes pouco transparentes, têm justificado a ausência de princípios democráticos nas tradições históricas e socioculturais de seu povo, culpando a ingerência ocidental para justificar seu poder autoritário. Entretanto, a real razão de tal conjunção parece ser a recusa por parte dos líderes locais em restringir a amplitude de seus poderes.

Por sua vez, insta ressaltar, ainda, como entrave ao processo de ampliação democrático, os graves problemas enfrentados pela imposição coercitiva do modelo ocidental liberal no processo de globalização, frutos, por vezes, de práticas imperialistas de controle de poder das nações economicamente desenvolvidas em face às mais vulneráveis. Conforme observa SOUZA (2006), o atentado terrorista de 11 de Setembro em Nova Iorque, nos Estados Unidos, a crescente onda de ataques terroristas em vários países ocidentais e o fortalecimento mundial do fundamentalismo islâmico são exemplos concretos desta celeuma de âmbito global.

Verifica-se, portanto, que o desafio de se alcançar pragmaticamente uma autêntica democracia é tarefa árdua e contínua. Tal processo demanda uma série de fatores, tais como: instituições comprometidas com os reais valores e princípios democráticos; o equilíbrio entre a limitação governativa e consentimento popular; e processos eleitorais competitivos e regulares que tutelem a igualdade política e protejam seus cidadãos contra um poder violador de direitos fundamentais. Uma forma de governo que se assenta no consentimento popular, onde a alternância de poder e a competitividade política sejam legalmente asseguradas e o povo tenha todos os seus direitos humanos e cívicos garantidos.

Para tanto, faz-se mister desenvolver e renovar a consciência jurídica e política dos governantes com base nos princípios éticos inerentes à ordem democrática, sob pena de se aferir a corrosão das instituições e a corrupção do corpo político, pela presença de comportamentos descompromissados com a ética e com a justiça social.

\section{GLOBALIZAÇÃO: PANORAMA HISTÓRICO}

Comprar e vender consiste em atividade antiga, iniciada nos primórdios dos tempos, pela prática comum entre os homens, de efetivar a troca de bens desejados por uns e excedentes para outros. Partiu da introdução de bens, com valor de troca, evoluindo para a instituição da circulação e economia monetária.

Aludida atividade teve grande avanço na Idade Média, com as Corporações de Mercadores que corriam cidades e instalavam-se em grandes feiras, sempre com o objetivo de tornar possível a mercancia. O comércio viabilizou a aproximação dos homens, além de possibilitar o crescimento do Estado (CASELA, 1997, p. 2-3). Incentivou as grandes navegações, sobretudo entre os séculos XV e XVII, dando início ao ciclo dos grandes descobrimentos, o que resultou no surgimento de civilizações até então desconhecidas, visando a ampliação do mercado consumidor e o acúmulo de riquezas por parte das nações colonizadoras.

Das feiras europeias da Idade Média, até se chegar aos grandes centros de compras da atualidade, as mutações sempre tiveram por objetivo ampliar a atividade lucrativa do comerciante ou empresário e, simultaneamente, facilitar o trabalho dos consumidores na aquisição de mercadorias e produtos. 
Contudo, conforme observa FERNANDES (2010, p. 22), a partir da metade da década de 1980, com o desmoronamento do bloco soviético, com o surgimento de novas tecnologias de comunicação e informação, a redução dos custos dos meios de transporte, e, sobretudo, com o desenvolvimento da internet, o fenômeno da globalização ganhou uma nova roupagem.

Outro aspecto que qualifica a globalização consiste na internacionalização da produção industrial que implica uma nova divisão internacional do trabalho, aliada à interdependência econômica cada vez mais acentuada dos países em relação aos mais diversos produtos - sejam primários, secundários ou terciários - bem como ao aumento dos movimentos migratórios mundiais e à competitividade dos mercados (Cox apud SOUZA, 2006).

Assim, com o passar do tempo, o vocábulo globalização, que inicialmente restringia-se à dimensão econômica, passou a ser entendido como uma realidade mais ampla e profunda, incluindo também a ciência e tecnologia, as relações sociais, políticas e culturais. Assume, deste modo, um significado muito mais abrangente, configurando uma “(...) multiplicidade de ligações e interconexões entre os Estados e as sociedades" (McGraw e Lewis, apud SOUZA, 2006).

Neste contexto, insta observar que historicamente a propriedade sempre foi o mais relevante instrumento do direito econômico. Contudo, em tempos de globalização, os contratos apresentam-se como o mais forte indicador econômico de produção e circulação de riqueza, dinamizando a economia. Com a utilização cada vez maior da rede mundial de computadores e da interdependência econômica cada vez mais acentuada entre os diversos países, surge um novo conceito de mercado, mais célere e dinâmico, que exigiu que o foco da circulação de riquezas saísse definitivamente da propriedade, estática como é, para o contrato, que passou de coadjuvante a personagem principal da economia mundial. Neste sentido, Roppo (apud COSTA, 2002, p. 631) afirma que “(...) o contrato é a veste jurídica das relações econômicas e por isso o instituto central da economia”.

Outrossim, as compras on-line passaram a ser um mecanismo muito utilizado pelos consumidores quando da aquisição de produtos ou serviços, com vantagens tanto para os que consomem, quanto para os que fornecem. Consumidores podem adquirir os mais diversos produtos, das mais diferentes localidades, sem deslocar-se de sua residência, com preços geralmente mais acessíveis. De igual modo, o fornecedor ao enveredar pelo comércio eletrônico acaba também tendo consideráveis vantagens, uma vez que os custos de uma loja virtual são menores do que uma loja física, além de atingirem, significantemente, um número consideravelmente maior de consumidores.

É cediço que o sistema de teleconferências e o avião contribuíram para minimização das barreiras físicas mercadológicas entre os povos. Mas é indiscutível que a internet propiciou uma verdadeira revolução no conceito de mercado e introduziu uma nova lex mercatoria, adaptada ao mundo globalizado de natureza supranacional. De fato, a internet transpôs barreira, abriu fronteiras e mercados. Propôs intercâmbio de informações, culturas, mercadorias, capital, tecnologia, investimentos, conhecimento (LUCCA e SIMÃO FILHO, 2000, p. 237).

Nesta conjuntura, incumbe também aos Estados Democráticos somar esforços para que os benefícios advindos da era da informação alcancem a todos indiscriminadamente, promovendo a democratização do amplo acesso aos meios eletrônicos de informação em nível global. 


\title{
6 GLOBALIZAÇÃO - AS DIVERSAS ABORDAGENS SOBRE O TERMO
}

Viu-se anteriormente que o conceito de globalização surgiu, como um fenômeno de extraordinário desenvolvimento das relações econômicas em nível mundial, sobretudo a partir de meados da década 1980, como um processo de aprofundamento internacional da integração e interdependência econômica, social, cultural e política entre os países, impulsionado pela redução de custos dos meios de transporte e de comunicação entre os países e pelo desenvolvimento da internet.

GIDDENS (1991, p. 70) observa que a globalização refere-se ao processo de conexão mundial entre diferentes regiões e contextos sociais que se interagem. Uma complexa amálgama de processos, que muitas vezes atua de maneira contraditória, conflituosa, suscitando novas formas de estratificação. Nesse sentido, o sociólogo expõe que:

\begin{abstract}
A globalização pode ser assim definida como a intensificação das relações sociais em escala mundial, que ligam localidades distantes de tal maneira que acontecimentos locais são modelados por eventos ocorrendo a muitas milhas de distância e vice-versa. Este é um processo dialético porque tais acontecimentos locais podem deslocar numa direção anversa às relações muito distanciadas que os modelam. A transformação local é tanto uma parte da globalização quanto a extensão lateral das conexões sociais através do tempo e do espaço (GIDDENS, 1991, p. 70).
\end{abstract}

GIDDENS (2002, p. 23) ressalva que o novo paradigma global contemporâneo é fruto do constante aumento das interdependências sociais e econômicas nas mais diversas esferas, diante de fenômenos que escapam ao controle isolado por parte dos Estados.

BECK (200o, p. 47), por sua vez, notabiliza a globalização como um paradigma de "interdependência transnacional", abandonando a "lógica dos mundos separados". Nesse sentido, a ideia de espaços isolados mutuamente delimitados por territórios, é relativizada. O autor qualifica a globalização como uma condição inevitável de intercâmbio humano na contemporaneidade.

Diante desse contexto, a globalização implica, outrossim, num processo no qual os Estados veem a sua identidade, sua soberania, suas relações de poder, suas orientações políticas, culturais e econômicas sofrerem interferências dos mais diversos atores transnacionais, tais como Organizações Internacionais - a Organização das Nações Unidas (ONU), Organização Mundial do Comércio (OMC), Organização Mundial da Saúde (OMS), Organizações NãoGovernamentais (ONGs), Empresas Transnacionais (ETNS), Banco Internacional para a Reconstrução e Desenvolvimento (BIRD), Fundo Monetário internacional (FMI), Organizações Sub-Regionais, como é o caso da Organização do Tratado do Atlântico Norte (OTAN), do Mercado Comum do Sul (Mercosul), do Mercado Comum Europeu, etc.

De fato, a interdependência constitui uma variável crescente e determinante no mundo globalizado. Robertson (apud BECK, 200o, p. 94), um dos principais expoentes da globalização, observa que a globalização não significa apenas "dês-localização, mas, também re-localização". Como consectário de tais premissas, a globalização compreende o diálogo de culturas diversas, as quais são sistematicamente redefinidas. Um “(...) processo dialético, não linear, e reflexivo que, insofismavelmente, sempre realça um novo significado para o 'local'” (FERNANDES, 2010, p. 69).

HABERMAS (2003, p. 104), por sua vez, observa a globalização como um processo de dissolução de fronteiras o qual não se restringe a um fenômeno econômico, acrescentando tratar-se de um modo de “(...) intensificação das relações de troca, de comunicação e de trânsito, para além das fronteiras nacionais”. Nesta perspectiva, a grande preocupação 
advinda dos processos irrefutáveis de globalização acaba sendo, justamente, a democracia. Nestes termos, explana HABERMAS (2001, p. 78).

\footnotetext{
O Estado territorial, a nação e uma economia constituída dentro das fronteiras nacionais formaram então uma constelação histórica na qual o processo democrático pôde assumir uma figura institucional mais ou menos convincente. Também só pôde se estabelecer no âmbito do Estado Nacional a idéia segundo a qual uma sociedade composta democraticamente pode atuar reflexivamente sobre si de modo amplo graças à ação de uma de suas partes. Hoje essa constelação é posta em questão pelos desenvolvimentos que se encontram no centro das atenções e que leva o nome de globalização.
}

Habermas (apud FERNANDES, 2010, p. 76) critica, peremptoriamente, os posicionamentos extremistas da globalização: tanto os radicalmente favoráveis aos imperativos funcionais do livre mercado mundial, como os adeptos a políticas nacionalistas e protecionistas, de um Estado que se "fecha a si mesmo", contrários a todo processo de interação global.

O autor assevera a prioridade de se fortalecer o processo político na era da globalização, e conferir enfoque apenas na lógica do mercado. Tal processo, na perspectiva de Habermas (apud FERNANDES 2010, p. 76), deriva de uma construção discursiva da opinião e da vontade de todos os participantes nos processos de democratização, com a necessária inclusão de todos os envolvidos, até mesmo os estrangeiros.

Porquanto, consoante pondera o filósofo (2003, p. 112): "Só poderemos enfrentar de modo razoável os desafios da globalização se conseguirmos desenvolver na sociedade novas formas de auto-condução democrática dentro da constelação pós-nacional." Faz-se, assim, necessário a criação de mecanismos democráticos aptos a sustentar “(...) uma política interna voltada para o mundo", respaldada por processos democráticos que lhe confiram legitimidade.

\section{A RELATIVIZAÇÃO DA SOBERANIA ESTATAL DIANTE DA GLOBALIZAÇÃO}

Um aspecto a se destacar na era da globalização refere-se à relativização e limitação da soberania dos Estados. O paradigma de interdependência mundial intensifica as dinâmicas e os processos de intercâmbio cultural, social, econômico e político, desterritorializando as relações sociais.

Por soberania entende-se como sendo a qualidade máxima de poder, por meio da qual as normas e decisões elaboradas pelo Estado prevalecem sobre as decisões emanadas dentro de seus limites territoriais. Nesse sentido, no âmbito interno, a soberania estatal traduz a superioridade de suas diretrizes na organização da vida comunitária. No âmbito externo, a soberania reflete a ideia de igualdade de todos os Estados na comunidade internacional, associada à sua independência nacional.

Conforme observa DALLARI (2011, p. 83), o conceito de soberania surgiu em 1576, com a obra "Les Six Livres de La Repúblique", de Jean Bodin, definindo-a como um “(...) poder absoluto e perpétuo de uma República”. Prescrevia a tese de que todo o poder do Estado pertencia ao monarca, e não poderia ser partilhado com mais ninguém - clero, nobreza ou povo.

Foi Rousseau quem transferiu o conceito de soberania da pessoa do governante para o povo, entendido como "corpo político ou sociedade de cidadãos". Nesta concepção, a soberania passa a ser entendida como um poder inalienável e indivisível, o qual deve ser exercido pela vontade geral, denominada soberania popular. Assim, quase dois séculos mais tarde, Rousseau introduz a noção de soberania popular baseando-se em um princípio que, 
de certa forma, subverte o conceito inaugural de soberania estabelecido por Bodin: "O povo, submetido às leis, deve ser o autor delas" (DERATHÉ, 2009, p. 87).

Insta ainda observar que as ideias de soberania popular exerceram grande influência na Revolução Francesa, proclamando o povo/nação como o originário detentor de qualquer poder político. Nesse sentido, a Declaração dos Direitos do Homem e do Cidadão (1789), em seu art. $3^{\circ}$, aduz: "O princípio de toda a soberania reside, essencialmente, na nação. Nenhuma operação, nenhum indivíduo pode exercer autoridade que dela não emane expressamente”.

Essa ideia, contudo, dissipou-se com as doutrinas que transferiram a soberania do povo/nação para o Estado, como ente dotado de personalidade jurídica, como o poder uno, indivisível e irrefutável.

Desde então, a noção jurídica de soberania orienta as relações entre Estados, na qualidade de potências, e enfatiza a necessidade de legitimação do poder político pela lei.

Contudo, com a internacionalização dos direitos humanos, mormente após a Segunda Guerra Mundial, houve uma delimitação da concepção da soberania nacional absoluta dos Estados, onde a proteção à pessoa humana, e os direitos a ela inerentes, não são mais vistos como uma questão interna de cada Estado, mas como um assunto universal, do qual todos os Estados devem respeitar e fazer cumprir, nas suas relações internas e externas.

Como corolário, a universalização da proteção dos direitos humanos, intensificada pelo processo de globalização, favoreceu, simultaneamente, o compromisso dos Estados perante a comunidade internacional no que diz respeito à proteção de direitos fundamentais em suas relações, e também à revisão do conceito de soberania que deve ser contextualizada, diante de uma nova perspectiva, muito mais abrangente e complexa do que o arcaico modelo que o caracteriza como poder absoluto, perpétuo e incontestável.

Nesta conjuntura, o princípio da dignidade da pessoa humana foi erigido à categoria de super-princípio, com carga axiológica máxima, a orientar a condução da democracia, na esfera local e global (BOBBIO, 1992, p. 87).

Discorrendo sobre a possibilidade da relativização da soberania estatal frente à violação de direitos humanos, PIOVESAN (2012, p.185) leciona:

\footnotetext{
A necessidade de uma ação internacional mais eficaz para a proteção dos direitos humanos impulsionou o processo de internacionalização desses direitos, culminando na criação da sistemática normativa de proteção internacional que faz possível a responsabilização do Estado no domínio internacional quando as instituições nacionais se mostram falhas ou omissas na tarefa de proteger direitos humanos.

O processo de internacionalização dos direitos humanos - que, por sua vez, pressupõe a delimitação da soberania estatal - passa, assim, a ser uma importante resposta na busca da reconstrução de um novo paradigma, diante do repúdio internacional às atrocidades cometidas no holocausto.
}

Importante observar que o princípio da soberania estatal continua sendo respeitado e admitido pela sociedade internacional e consagrado pela Carta das Nações Unidas. Os Estados nascem e permanecem iguais em direitos, imperando no Direito Internacional a noção da igualdade soberana entre os povos.

Entretanto, é preciso considerar que a tutela aos direitos humanos representa uma nova dimensão da soberania estatal frente à sociedade internacional globalizada, que não se resume ao silogismo simplista de mera oposição à autoridade dos Estados na gestão de suas decisões internas.

Nesta perspectiva, a ingerência da comunidade internacional surge supletivamente, apenas quando o Estado se abstém de sua obrigação legal, comprometida internacionalmente, de proteger os direitos fundamentais em suas relações. Como um instrumento jurídico, 
inserto na lógica da ética e da solidariedade entre as nações, para garantir o cumprimento de direitos formalmente pré-estabelecidos, fazendo com que o Estado cumpra sua função de efetivamente tutelar o direito à vida.

O novo paradigma de soberania estatal demanda o entendimento de um Estado não isolado, mas membro de uma comunidade sistêmica internacional. Deve, pois, respeitar os compromissos e tratados internacionais por ele firmados, bem como o efetivo respeito a direitos humanos, nas suas relações internacionais, passando pela defesa da democracia e pelo fortalecimento das instituições, servindo como diretriz a atuação de políticas públicas e econômicas.

Sendo assim, faz-se mister repensar a soberania no plano do direito internacional, a fim de se conjecturar à ingerência internacional, abandonando em parte, consoante observa BACHELET (1995, p. 22), a ortodoxia da soberania absoluta estatal em proveito de uma nova forma de gestão dos Estados na perspectiva global, com o propósito de se preservar o direito à vida digna.

Constata-se, pois, que a universalização da proteção dos direitos humanos na era globalizada provocou a necessidade da revisão do obsoleto conceito de soberania, o qual precisa ser contextualizado a esta nova perspectiva, muito mais hermética daquela notoriamente difundida, que a caracteriza como um poder absoluto, perpétuo, incontestável.

\section{OS DESAFIOS DA DEMOCRACIA NA ERA GLOBALIZADA}

A democracia no contexto da globalização é empreendida por uma variedade de atores, como um processo dialético multifacetado, o qual compreende forças globais, estatais e não estatais, que se interagem e se influenciam, reciprocamente.

Neste aspecto, a globalização tem consequências visíveis nos processos de consolidação da democracia na esfera mundial, ora constituindo um fator de fomento à sua promoção, ora um elemento de fragmentação de seus caracteres.

Aludida constatação compreende a maneira que os Estados, enquanto entidades singulares no processo global, podem constituir um entrave ou um disseminador para a consolidação mundial da democratização, corroborando o silogismo que a democracia, contextualizada territorialmente num Estado, não consegue permanecer imune aos fluxos multifatoriais transnacionais promovidos pela globalização.

Diante de tais premissas, para que a globalização constitua efetivamente num instrumento de promoção da democracia, os fundamentos democráticos devem ser fomentados e ampliados para além das fronteiras territoriais dos Estados. Na era globalizada, tais fundamentos não podem restringir-se à dualidade Estado versus povo, circunscritos aos limites territoriais de cada país, cabendo aos Estados detentores de uma democracia mais solidificada instrumentalizar a difusão do processo democrático a nível supranacional.

Desse modo, a interdependência entre as nações em âmbito regional e global faz com que as decisões políticas nos mais diversos Estados Democráticos não se limitem a repercussões somente internas. As linhas democráticas entre o interno e o externo tornaramse mais tênues, assim como as relações internacionais tornaram-se mais complexas. Muitas vezes, as resoluções proferidas por determinados Estados acabam transcendendo seus limites territoriais geográficos, sendo imprescindível, conforme observa HELD (1992, p. 6) “(...) redefinir o significado e o lugar da democracia, em relação a uma série de estruturas e processos locais, regionais e globais”. 
Afere-se, entretanto, que o êxito deste processo global de democratização demanda a somatória de alguns fatores, tais como o comprometimento das autoridades políticas nacionais, o fortalecimento das instituições democráticas, a operacionalidade da atividade legislativa, administrativa e judiciária dos Estados, além do engajamento das sociedades civis organizadas.

Também as organizações e comunidades internacionais têm se revelado importantes instrumentos de estabilidade e pacificação social, por meio de atividades de assistência e fiscalização aos processos reformistas legais, conferindo amparo jurídico-legal à democratização dos mais diversos países. Além do mais, o caráter multidimensional das suas abordagens, incluindo aspectos políticos, sociais, sanitários, culturais, jurídicos e econômicos dos Estados envolvidos, contribui para a consolidação deste processo. As sanções econômicas e políticas por elas aplicadas a regimes ditatoriais também constituem um relevante instrumento de fortalecimento da democracia no âmbito global, provocando o enfraquecimento, a instabilidade e a erosão dos regimes ditatoriais.

Importante, outrossim, notar que o fortalecimento das organizações internacionais favoreceu o diálogo entre Estados, além de propiciar um maior equilíbrio nas relações diplomáticas (HELD, 1992, p. 6-7). Além do mais, pelo fato de implicarem regras e objetivos comuns às mais diversas nações, suscitam uma maior interação entre os seus membros, propiciando princípios de cooperação e mútuo auxílio.

\section{O PAPEL DA DEMOCRACIA NA REDUÇÃO DAS DESIGUALDADES SOCIAIS GLOBAIS}

No mundo globalizado, existem uma série de mazelas sociais e ambientais que afetam as pessoas numa escala extra fronteiras, porque universais são muitas das consequências advindas do desequilíbrio mundial. $\mathrm{O}$ aquecimento global, os graves problemas ambientais relacionados à água, ao lixo, à qualidade do ar, à perda da diversidade biológica, ao crescimento populacional desordenado, ao fluxo migratório irregular, à disseminação de doenças, à miséria, à degradação dos recursos ambientais são alguns exemplos concretos de tal constatação.

Tais questões afetam a qualidade de vida das pessoas dos mais diversos países e não respeitam limites geográficos, atingindo toda comunidade planetária. Extrapolam fronteiras e por isso demandam mobilidade e esforço comum. Como corolário, a comunidade internacional elenca uma série de princípios e obrigações cogentes as quais devem ser respeitadas e efetivamente cumpridas pelos Estados.

Assim, neste processo de fortalecimento global da democracia, é outrossim imprescindível o engajamento e a contribuição de Estados Democráticos mais ricos, auxiliando os países economicamente mais pobres e periféricos a superar seus graves problemas sociais, econômicos e ambientais, em prol do princípio da cooperação e da solidariedade internacional.

A efetivação do princípio da cooperação nas relações internacionais pressupõe o intercâmbio de tecnologias, conhecimento científico e auxílio financeiro por parte das grandes potências econômicas na proteção de danos globais.

Consoante observa OLIVEIRA (2007, p. 4)

E nessa idéia de local/regional se precisa considerar, que apesar de alguns dos 'ritos e imposições globalizantes' seguirem firmes na tentativa de homogeneizar o mundo, as diferenças entre países e continentes se reafirma cotidianamente; são diferenças de história, de construção dos processos civilizatórios, culturais e políticos, e, como não poderia deixar de ser, de posição econômica no cenário mundial. 
Afere-se, pois, que com as transformações sociais, econômicas e políticas ocorridas no final do século XX e início de XXI advindas da globalização, a discussão entre o modelo de democracia representativa ou democracia direta perde um pouco a relevância. Ela assume outra feição: como articular os avanços da democracia política com a criação de condições mínimas de bem-estar social no mundo globalizado.

Como observa Bobbio (1987, p. 155-156), o processo de alargamento da democracia na sociedade contemporânea não deve ocorrer apenas pela integração da democracia representativa com a democracia direta, mas, sobretudo, pela extensão da democratização a corpos diferentes daqueles propriamente políticos. Neste sentido, assinala o referido autor:

(...) pode-se dizer que, se hoje se deve falar de um desenvolvimento da democracia, ela consiste não tanto na substituição da democracia representativa pela democracia direta, (...) mas na passagem da democracia na esfera política para a democracia na esfera social.

Neste diapasão, a ampliação da democracia deve, pois, necessariamente, estar vinculada com a redução das disparidades sociais. Os princípios democráticos ficam demasiadamente inócuos, esvaziam-se se a democracia for reduzida à simples regime político.

Além do mais, a história tem demonstrado que extremas desigualdades sociais funcionam como um fator limitativo da democracia. A miséria, a acentuada desigualdade econômica ocasiona, irrefutavelmente, a desigualdade política. Nessa perspectiva, deve ser adicionada à ampliação da dimensão política da democracia um outro elemento de não menor relevância: a condição social e econômica dos atores sociais que estão envolvidos no processo democrático.

É imprescindível que a democracia leve em consideração as condições de vida digna de seu eleitorado, seu grau de escolaridade, suas conjunções de participar das decisões políticas e exercer a fiscalização de seus representantes. Por sua vez, as normas do processo democrático, quando forem definidas apenas por uma elite detentora de poder, dificulta não apenas a participação política mais abrangente da sociedade civil, como o efetivo acesso igualitário aos bens materiais e culturais.

Insta, ainda, observar que, nos países de democracia mais solidificada, sobretudo os de capitalismo avançado, as políticas sociais foram fruto das mudanças estruturais ocasionadas pela modernização dos processos de trabalho, impostas pela denominada terceira revolução industrial que resultou na desmercantilização da força laborativa.

Conforme observa Offe (apud CABRAL NETO, 1997, p. 302-304), as políticas sociais apresentarem-se nesta conjuntura como um remédio para premência diante das modificações operacionalizadas no processo produtivo da época, obrigando o Estado a implementá-las, para que aqueles trabalhadores excluídos do mercado formal de trabalho pudessem sobreviver, até se adequarem ao novo paradigma laboral.

CERRONI (1993, p. 155) explana que: "O Estado de Bem-Estar Social cresce sobre a onda de grandes reivindicações e, por isso, também constitui uma resposta cautelar às grandes agitações verificadas após a primeira guerra mundial”.

Constata-se, pois, que a origem das políticas sociais, próprias do Estado Social de Direito, deve ser entendida como resultado da desintegração das formas tradicionais de trabalho, decorrentes das mudanças estruturais aferidas nas sociedades capitalistas da época (Offe apud CABRAL NETO, 1997, p. 304). Uma necessidade da democracia controlar as grandes massas e manter a pacificação, evitando o caos social.

Como corolário deste silogismo, até meados do século $\mathrm{XX}$, todos os Estados Democráticos de Direito incorporaram os direitos de segunda geração em seus textos 
constitucionais, exigindo dos Estados uma postura mais ativa em relação a determinadas necessidades socioeconômicas de seus cidadãos.

Neste contexto, a Constituição Brasileira de 1988 celebra, em seus artigos 170 e seguintes, o sistema econômico capitalista, no qual os fatores de produção pertencem aos agentes privados, que deles dispõem e podem valer-se para a obtenção de lucro. Contudo, o modelo de economia capitalista celebrado pela Carta de 1988 não compreende um capitalismo liberal puro, nos moldes da doutrina liberal clássica de Adam Smith, neoclássica de Marshall, ou neoliberal de Stigler e Friedman. Mas um Estado Democrático de Direito que celebra sim a livre iniciativa, o livre mercado, a liberdade de concorrência e a propriedade privada, mas que também é comprometido com os deveres de concretização da dignidade da pessoa humana, da função social da propriedade, da defesa do meio ambiente, da justiça social, do pleno emprego e da redução das desigualdades regionais e sociais.

O diálogo da democracia com a economia acentua-se, sobretudo, levando-se em conta o fenômeno da globalização do mercado. Neste sentido, não cabe mais às grandes potências democráticas utilizarem-se do seu poder econômico apenas como instrumento de dominação, de imposição de sua linguagem, de seus interesses. Os genuínos princípios democráticos devem definir e orientar o comércio e as relações internacionais das diferentes nações. Caso contrário, acender-se-ia o notório e arcaico arquétipo intervencionista e colonialista das nações economicamente desenvolvidas, as quais impunham arbitrariamente suas decisões em prol de seus próprios interesses. Conforme ressalta Hall (apud BECKER e MIRANDA, 1997, p. 274):

(...) nos países em desenvolvimento, tais conflitos foram gerados ou exacerbados pelo regime colonial, sob o qual a extração de recursos e os sistemas produtivos estavam direcionados para atender aos interesses das nações colonizadoras às expensas das colonizadas, muitas vezes de forma mais violenta e brutal.

A missão dos Estados Democráticos neste cenário consiste, outrossim, em instrumentalizar a conquista da justiça social e respeito a direitos fundamentais nas suas relações internacionais, reduzindo antíteses sociais.

Isto se torna possível com a devida concretização dos princípios essencialmente democráticos, como a liberdade, a igualdade, a dignidade da pessoa humana, cabendo aos Estados a função de salvaguardar, na ordem jurídica interna e nas suas relações transnacionais, tais valores os quais se apresentam como imprescindíveis ao bom ordenamento social, nacional e supranacional.

É cediço que a precária dotação inicial de recursos econômicos desiguala efetivamente as possibilidades dos cidadãos. Isso não quer dizer que o homem seja fruto exclusivamente destas circunstâncias, mas sim que elas muito interferem no desenvolvimento do seu potencial.

Neste diapasão, entra o papel da democracia, no sentido de atuar não apenas na regularização de uma igualdade formal, consagrada no liberalismo clássico, mas, sobretudo, na efetivação de uma igualdade material, inspirada na lição secular aristotélica, a qual preconiza que a lei deve tratar igualmente os iguais e desigualmente os desiguais, na medida de suas desigualdades.

Isto porque num Estado Democrático de Direito ativo, efetivador de direitos humanos, busca-se uma igualdade real, concreta entre os bens da vida, diversa daquela apenas formalizada perante as leis, devendo os Estados colocarem seus instrumentos jurídicos e legais a favor destes grupos marginalizados, com o objetivo de viabilizar as mesmas possibilidades econômicas asseguradas aos demais membros da população. 
Por isso, é necessária uma ação conjunta das nações em favor da defesa da dignidade humana no âmbito da globalização da economia, incumbindo aos Estados Democráticos a indispensável função de fomentar suas relações comerciais, mas também domesticar o uso desenfreado do poder econômico, impedindo que ele sirva apenas como instrumento de dominação de poder.

\section{CONCLUSÃO}

Afere-se, portanto, que a relação entre a globalização e democracia consiste num processo dialético, que envolve uma série de atores, estatais e não estatais, que se interatuam e se inspiram, mutuamente, pressupondo uma constante e mútua cooperação e fiscalização. Tal silogismo suscita o desfecho que a construção democrática não deve restringir-se aos limites territoriais de determinado Estado, devendo, pois, ultrapassar suas fronteiras geográficas.

O ensaio demonstrou inexistir um conceito unificado de democracia, do mesmo modo que o modelo democrático não deve ser entendido como um modelo perfeito e acabado. As diferentes concepções do termo e as disparidades pragmáticas encontradas na sua materialização são frutos das diversas expectativas políticas, sociais e econômicas, das várias teorias existentes, dos diferentes processos históricos civilizatórios, somadas às conjunturas nacional e global.

Constatou-se, na sociedade globalizada, as consideráveis adversidades enfrentadas pelos Estados Democráticos na efetivação de princípios e fundamentos democráticos, incutindo sobre a real legitimidade popular de muitos dos Estados formalmente intitulados de democratas.

Neste contexto, denota-se que inúmeros são os percalços enfrentados no processo de democratização no contexto global. As intervenções de caráter neoimperialista dos países desenvolvidos nos países periféricos; o apoio a regimes autoritários em prol de interesses nacionais exclusivamente econômicos; a corrupção enraizada nas instituições públicas e privadas; as políticas autoritárias ainda existentes em Estados islâmicos; a democracia fragilizada de alguns países africanos e sul americanos; as novas formas de fundamentalismo; o terrorismo; os graves problemas sociais advindos da crescente imigração ilegal nos países europeus; as gigantescas desigualdades econômicas existentes no mundo são exemplos concretos de entraves ao processo de democratização a nível mundial. Práticas de uma exegese democrática, interpretada adulteradamente, que minam as bases de um entendimento comum de democracia enquanto ética global.

Institucionalizar uma sociedade democrática é, inquestionavelmente, um mister árduo e constante. Demanda mudança de arcaicos e pérfidos hábitos, impõe planejamento por parte do poder público, ao mesmo tempo que pressupõe comprometimento conjunto dos Estados e da sociedade.

Contudo, tal tarefa quando alcançada opera uma mudança paradigmática nas relações sociais, pois representa um governo comprometido com a concretização do bem comum, com a construção de uma sociedade consciente de seus deveres e direitos, e com a concretização de genuínos valores e fundamentos éticos democráticos.

Aferiu-se, por sua vez, que a democratização da globalização pode ser instrumentalizada e fomentada por diversos meios, como: o engajamento e o esforço maior dos Estados em assuntos de interesses universais; a valorização das instituições e das sociedades civis organizadas; o auxílio das organizações internacionais na promoção da expansão democrática; 
e uma representatividade mais relevante dos países periféricos nas decisões de organismos internacionais.

Pois, consoante ressalva DAHL (2001, p. 73), a democracia não consegue garantir que os indivíduos em sociedade “(...) sejam felizes, prósperos, saudáveis, sábios, pacíficos ou justos. Atingir esses fins está além da capacidade de qualquer governo - incluindo-se um governo democrático"

Contudo, apesar de todas as suas limitações, imprecisões e paradoxos, a democracia continua sendo o melhor regime de governo até então existente. Uma forma política respaldada no consentimento popular, que permite a alternância de poder, a participação e a fiscalização popular nas decisões de governança, salvaguardando os direitos fundamentais, com vistas à concretização de uma ordem social mais justa e igualitária.

Outrossim, existem questões e interesses que extrapolam as fronteiras territoriais de determinados Estados, como o respeito a direitos humanos, questões de segurança e saúde pública mundial - como armas nucleares, químicas e bacteriológicas - a defesa do meio ambiente, da paz mundial, dos direitos das mulheres, das minorias, etc. Exemplos concretos de interesses considerados universais, de consciência comum de uma comunidade global, os quais necessitam do engajamento e da mobilidade dos Estados, na esfera local, regional e mundial.

Neste diapasão, em tempos de globalização, devem os Estados Democráticos de Direito atuarem também enquanto transformador das gigantescas disparidades sociais e econômicas existentes entre as diversas nações, com a instrumentalização de uma globalização mais altruísta e solidária, diante da evidente impossibilidade da coexistência de igualdade política com extrema desigualdade econômica e social.

Como consectário, é imprescindível que as relações econômicas, necessárias

à subsistência e bem-estar dos homens, sejam reguladas por Estados Democráticos comprometidos com a justiça social e a igualdade material, remetendo sempre o homem como o protagonista, tendo por referência normativa maior o princípio da dignidade da pessoa humana.

E, neste sentido, a democracia enfrenta também o desafio de contribuir na construção de uma "sociedade global" mais ordenada e equilibrada, com base em princípios de justiça e bem estar social, impedindo que o poder econômico elimine as possibilidades de aflorar valores exclusivamente financeiros, e auxiliando na construção de um mundo mais humanizado e menos desigual.

\section{REFERÊNCIAS BIBLIOGRÁFICAS}

BACHELET, Michel. Ingerência ecológica: direito ambiental em questão. Tradução de Fernanda Oliveira. Rio de Janeiro: Instituto Piaget, 1995.

BECKER, Bertha K. e MIRANDA, Mariana. A Geografia política do desenvolvimento sustentável. Rio de Janeiro: Editora UFRJ, 1997.

BOBBIO, Norberto. O futuro da democracia. São Paulo: Paz e Terra, 2000.

BOBBIO, Norberto. A era dos direitos. Trad. Carlos Nelson Coutinho. Rio de Janeiro: Campus, 1992. 
BOBBIO, Norberto. Estado governo sociedade; para uma teoria geral da política. 2. ed.. Rio de Janeiro: Paz e Terra. 1987.

BOBBIO, Norberto. Liberalismo e democracia. 4. ed. São Paulo: Brasiliense. 1993.

CABRAL NETO, Antônio. Democracia: velhas e novas controvérsias. Estudos de Psicologia. 1997, 2(2), p. 287-312. Disponível em: http://www.scielo.br/scielo.php?script=sci_ arttext\&pid=S1413-294X1997000200005. Acesso em: 21 dez 2019.

CASELA, Paulo Borba. Globalização, direito e estado: introdução. Artigo publicado em obra coletiva sob o título Globalização. São Paulo: Aduaneiras, 1997.

COSTA, Judith Martins. Mercado e Solidariedade Social entre Cosmos e Táxis: A boa-fé nas relações de consumo in: A Reconstrução do Direito Privado: Reflexões dos princípios, diretrizes e direitos fundamentais constitucionais no direito privado. São Paulo: Editora Revista dos Tribunais, 2002.

CERRONI, Umberto. Política: métodos, teorias, processos, sujeitos, instituições, categorias. Tradução de M. A. Nogueira. São Paulo: Brasiliense, 1993.

DAHL, Robert A. Sobre a democracia. Tradução de Beatriz Sidou. Brasília: UnB, 2001.

DALLARI, Dalmo de Abreu. Elementos de Teoria Geral do Estado. 30 ed. São Paulo: Saraiva, 2011.

DERATHÉ, Robert. Jean-Jacques Rousseau e a ciência política de seu tempo. Tradução de Natalia Maruyama. São Paulo: Barcarolla, 2009.

FARIA, José Eduardo. O direito na economia globalizada. São Paulo: Malheiros, 2002.

FERNANDES, Bernardo Gonçalves. Globalização, Direito Constitucional, Democracia e Sociedade: uma "breve reflexão" no "pano de fundo" da modernidade ou da pós-modernidade? Do estado nacional ou pós-nacional? In: Revista da Faculdade de Direito UFMG. n. 56, jan./jun. Belo Horizonte: Universidade Federal de Minas Gerais - UFMG, 2010. p. 63-100. Disponível em: https://www.direito.ufmg.br/revista/index.php/revista/article/view/112/104. Acesso em: 28 dez 2019 .

FERNANDES, Bernardo Gonçalves. Direito Constitucional e Democracia: entre a globalização e o risco. Rio De Janeiro: Lumen Juris, 2010.

FRANÇA, Assembleia Nacional. Declaração dos Direitos do Homem e do Cidadão. Disponível em: http://www.direitoshumanos.usp.br/index.php/Documentos-anteriores${ }_{0} \mathrm{C}_{3} \%$ Ao-cria $\% \mathrm{C}_{3} \% \mathrm{~A}_{7} \% \mathrm{C}_{3} \% \mathrm{~A}_{3}$-da-Sociedade-das-Na ${ }_{0} \mathrm{C}_{3} \% \mathrm{~A}_{7}{ }_{0} \mathrm{C}_{3} \% \mathrm{~B}_{5}$ es-at $\% \mathrm{C}_{3} \% \mathrm{~A}_{9}-1919 /$ declaracao-de-direitos-do-homem-e-do-cidadao-1789.html. Universidade de São Paulo USP. Biblioteca Virtual de Direitos Humanos. Acesso em: 05 dezembro 2019.

GIDDENS, Anthony. Mundo em descontrole: o que a globalização está fazendo de nós. Tradução de Maria Luiza de A. Borges. Rio de Janeiro: Record, 2002. 
GIDDENS, Anthony. As consequências da modernidade. Tradução de Raul Fiker. São Paulo: UNESP, 1991.

HABERMAS, Jürgen. A Era das Transições. Tradução de Flávio Benno Siebeneichler. Rio de Janeiro: Tempo brasileiro, 2003.

HABERMAS, Jürgen. A Constelação pós-nacional. Tradução de Mario Seligmann. São Paulo. Lmundi, 2001.

HELD, David. Democracia e Globalização. In: Revista Novos Rumos. Tradução de Edsel Brito - Revista Leviatán. Madri. Ano 9, n. 23. p. 5-8. São Paulo: UNESP, 1992.

KELSEN, Hans. A democracia. Tradução de Ivone Benedetti. São Paulo: Martins Fontes, 2000.

LUCCA, Newton de e SIMÃO FILHO, Adalberto. Direito \& Internet - Aspectos jurídicos relevantes. São Paulo: Edipro, 2000.

MONTESQUIEU, Charles-Louis de Secondat. Do espírito das leis. In Os Pensadores. 2. ed. São Paulo: Abril Cultural. 1979.

OLIVEIRA, Carla Montefusco de. Desenvolvimento Sustentável: uma discussão ambiental e social. III Jornada Internacional de Políticas Públicas. Maranhão, 28 a 30 de agosto 2007. Disponível em: http://www.joinpp.ufma.br/jornadas/joinppIII/html/Trabalhos/ EixoTematicol/b181e2fe3f9b7aogd9oe_Carla\%2oMontefusco\%2ode\%2oOliveira.pdf, Acesso em: 05 nov 2019.

PIOVESAN, Flávia. Direitos Humanos e o Direito Constitucional Internacional. 13. ed. São Paulo: Saraiva, 2012.

ROUSSEAU, Jean-Jacques. Do contrato social. 1983. In Os pensadores. 3. ed., p. 15-145. São Paulo: Abril Cultural, 1983.

SANTOS, Boaventura de Souza (org.). A Globalização e as Consequências sociais. São Paulo: Cortez, 2002

SARLET, Ingo Wolfgang. A eficácia dos direitos fundamentais: uma teoria geral dos direitos fundamentais na perspectiva constitucional. 10 ed. Porto Alegre: Livraria do Advogado, 2009.

SOUZA, Fernando de. A democracia, face política da globalização? 2006. Rev. bras. polít. int. v.49 n.1 Brasília jan./jun. 20o6. Disponível em: http://www.scielo.br/scielo.php?script=sci_ arttext\&pid=So034-73292006000100001. Acesso em: 07 dez 2019.

TOCQUEVILLE, Alexis de. A Democracia na América: leis e costumes - Livro I. São Paulo: Martins Fontes, 2014. 